\title{
The Role of Physiological and Operative Severity Score for the Evaluation of Mortality and Morbility in the Stratification of Abdominal and Extrab- dominal Surgery Patients
}

\author{
D. Alampi ${ }^{*}$, F. Creazzola, P. Sgarlata, V. Defraia, C. Runfola and G. Pinto \\ Faculty of Medicine, University of Rome La Sapienza, S. Andrea Hospital, Via di Grottarossa 1035, 00189, Rome, Italy
}

\begin{abstract}
Background: Adequate stratification and scoring of risk is essential to optimize clinical practice; the ability to predict operative mortality and morbidity is important to choose the gold therapy and a proper use of resources. The Physiological And Operative Severity Score For The Evaluation Of Mortality And Morbility (POSSUM) has been proved to be the most appropriate scoring system in providing an estimation of postoperative mortality for patients undergoing abdominal surgery. The aim of our study was to verify the predictive accuracy of POSSUM in patients undergoing elective extrabdominal surgery.
\end{abstract}

Patients and Methods: Our study included 189 patients, all admitted to Intensive Care Unit (ICU) at S.Andrea Hospital in Rome. The sample was divided in 2 groups: group A, abdominal surgery; group B, extrabdominal surgery.

All types of surgery were included except for cardiac surgery, pediatric surgery and urgent surgery. For each patient was determined the POSSUM score. Age, sex and preoperative information, surgical diagnosis, severity of the procedure , time of hospitalization, post operative complications were also recorded.

The two groups were divided in classes, based on the rate of morbidity and mortality. For each class was calculated the relation between predicted and observed deceases, and the relation between predicted and observed complications, scoring 1 if present and 0 if not present, in order to assign a reliability score to each group. Furthermore, basing on the length of stay, were individuated three subgroups of patients: hospitalization $<3$ days, between 4 and 7 days, $>7$ days. For each group was evaluated the correlation between observed and predicted morbidity.

Results: Above 189 patients, 49 developed postoperative complications, with a real morbidity rate of $25,9 \%$ (95\%CI: 20\%-32\%) and a predicted rate of 51,3\%; the relation between observed and predicted complications (O/P ratio) was 0,50 . For the A group the O/P ratio was 0,45, with a real morbidity rate of 25,53\% (95\% CI: $17 \%-34 \%$ ) over a predicted rate of $56,4 \%$. In the $\mathrm{B}$ group the $\mathrm{O} / \mathrm{P}$ ratio was 0,53 , with a real morbidity rate of $26,31 \%(95 \% \mathrm{CI}: 17,2 \%-34,8 \%)$, and a predicted rate of $49 \%$. Above 189 patients, 5 deceased, with a real mortality rate of 2,64\% (95\% CI: 0,4\%-4,8\%), over a predicted rate of $16,4 \%$; the relation between observed and predicted deaths $(\mathrm{O} / \mathrm{P}$ ratio) was 0,16 . For the $\mathrm{A}$ group, $\mathrm{O} / \mathrm{P}$ ratio was 0,11 , with a real mortality rate of $2,1 \%(95 \% \mathrm{CI}: 0-5 \%)$ over a predicted rate of $18,08 \%$; for the $\mathrm{B}$ group, O/P ratio was 0,25 , with a real rate of $3,16 \%(95 \%$ CI: $0-436,7 \%)$ over a predicted rate of $12,63 \%$. Correlation between time of hospitalization and POSSUM morbidity has an average strength expressed by a $\rho$ value $=0,4$.

Conclusion: Observed data confirm the possibility to extend the POSSUM score in the stratification of patients undergoing extrabdominal surgery. Even though it overpredicted the value of morbidity and mortality, as widely known, POSSUM score shows an impressive uniformity and concordance between the main groups A and B. Furthermore, there is a good correlation between time of stay in ICU and the POSSUM morbidity.

Our results suggest that POSSUM can be an adequate perioperative mean, recommended to evaluate the real condition of a patient after surgery and to determine the requirement of an admission to the postoperative ICU.

Keywords: POSSUM, severity score system, extra-abdominal surgery, post-operative complications, intensive care unit, morbility, mortality.

\section{BACKGROUND}

Adequate stratification and scoring risk is essential to optimize clinical practice in every medical and surgical field;

*Address correspondence to these authors at the Faculty of Medicine, University of Rome La Sapienza, S. Andrea Hospital, Via di Grottarossa 1035, 00189, Rome, Italy; Tel: 06-33775742; Fax: 06-33775071;

E-mail:d.ala@tiscali.it the ability to predict operative patient's mortality and morbidity is important to choose the gold therapy and a proper use of resources.

The Physiological And Operative Severity Score For The Evaluation Of Mortality And Morbility (POSSUM) has been proved to be the most appropriate scoring system to estimate the postoperative mortality in patients undergoing abdominal surgery [1]. 
Table 1. POSSUM Score

\begin{tabular}{|c|c|c|c|c|}
\hline Variable & 1 & 2 & 4 & 8 \\
\hline Age,y & $\leq 60$ & $61-70$ & $\geq 71$ & NA \\
\hline Cardiac signs & No failure & $\begin{array}{l}\text { Diuretic,digoxin,antianginal, } \\
\text { or hypertensive therapy }\end{array}$ & $\begin{array}{l}\text { Peripheral edema; warfarin } \\
\text { sodium therapy }\end{array}$ & Raised jugular venous pressure \\
\hline Chest radiograph (heart) & NA & NA & Borderline cardiomegaly & Cardiomegaly \\
\hline Respiratory history & No dyspnea & Dyspnea on exertion & Limiting dyspnea (1 flight) & Dyspnea ar rest $($ rate,$\geq 30 / \mathrm{min})$ \\
\hline Chest radiograph (lung) & NA & Mild COPD & Moderate COPD & Fibrosis or consolidation \\
\hline $\begin{array}{l}\text { Mean systolic blood pres- } \\
\text { sure, } \mathrm{mmHg}\end{array}$ & $110-130$ & $131-170$ & $\geq 171$ & $\leq 89$ \\
\hline Pulse, beats/min & $50-80$ & $\begin{array}{c}81-100 \\
40-49\end{array}$ & $101-120$ & $\begin{array}{l}\geq 121 \\
\leq 39\end{array}$ \\
\hline Glasgow coma scale & 15 & $12-14$ & $9-11$ & $\leq 8$ \\
\hline Hemoglobin, $\mathrm{g} / \mathrm{dl}$ & $13.0-16.0$ & $\begin{array}{l}11.5-12.9 \\
16.1-17.0\end{array}$ & $\begin{array}{l}10.0-11.4 \\
17.1-18.0\end{array}$ & $\leq 9.9$ \\
\hline $\begin{array}{l}\text { White blood cell count, } \\
\qquad \times 10^{3} / \mu 1\end{array}$ & $4.0-16.0$ & $\begin{array}{c}10.1-20.0 \\
3.1-3.9\end{array}$ & $\begin{array}{l}\geq 20.1 \\
\leq 3.0\end{array}$ & NA \\
\hline Serum urea, $\mathrm{mg} / \mathrm{dl}$ & $\leq 21$ & $22-28$ & $29-41$ & $\geq 42$ \\
\hline Serum sodium, $\mathrm{mEq} / 1$ & $\geq 136$ & $131-135$ & $126-130$ & $\leq 125$ \\
\hline Serum potassium, mEq/1 & $3.5-5.0$ & $\begin{array}{l}3.2-3.4 \\
5.1-5.3\end{array}$ & $\begin{array}{l}2.9-3.1 \\
5.4-5.9\end{array}$ & $\begin{array}{l}\leq 2.8 \\
\geq 6.0\end{array}$ \\
\hline Electrocardiogram & Normal & NA & Atrial fibrillation (rate, 60-90) & $\begin{array}{c}\text { Any other abnormal rhythm or } \\
\geq 5 \text { ectopics/min Q waves or } \\
\text { ST/T-wave changes }\end{array}$ \\
\hline Operative severity & Minor & Moderate & Major & Major plus \\
\hline Multiple procedures & 1 & NA & 2 & $>2$ \\
\hline Total blood loss, $\mathrm{ml}$ & $\leq 100$ & $101-500$ & $501-900$ & $\geq 1000$ \\
\hline Peritoneal soiling & None & Minor (serous fluid) & Local pus & $\begin{array}{l}\text { Free-bowel content, pus, or } \\
\text { blood }\end{array}$ \\
\hline Presence of malignancy & None & Primary only & Nodal metastases & Distant metastases \\
\hline Mode of surgery & Elective & NA & $\begin{array}{l}\text { Emergency resuscitation within } \\
\qquad 2 \mathrm{~h} \text { possible } \\
\text { operation }<24 \mathrm{~h} \text { after admission }\end{array}$ & $\begin{array}{l}\text { Emergency (immediate surgery } \\
\qquad<2 \text { h needed) }\end{array}$ \\
\hline
\end{tabular}

Possum score consists of 18 parameters, 12 physiological and 6 surgical, and was created by G. P. Copeland et al. in 1991 Table 1. Since then, it has been spreading extensively in Great Britain and in other countries for the surgical trend to acquire accurate data of operative outcome and to supply to patients as much information as possible in order to achieve an informed consent.

Moreover, a correct scoring system could become an essential tool for the clinical governance, that is a strategy, used by healthcare organizations, to be responsible for the continuous improvement of services quality and achievement-maintenance of high standards of care $[2,3]$.
In addition, it is demonstrated that patients admitted to ICU on basis of pre-operative POSSUM score, have experienced less post-operative complications [4].

The validity of this scoring system was verified by a comparison between predicted and observed data [5].

The aim of our study was to prove the same predictive meaning of POSSUM in patients undergoing both abdominal surgery and extra-abdominal surgery, in order to use this score as one of the criteria for the admission of all surgical patients in Post-operative Intensive Care, in addition to clinical evaluation. 


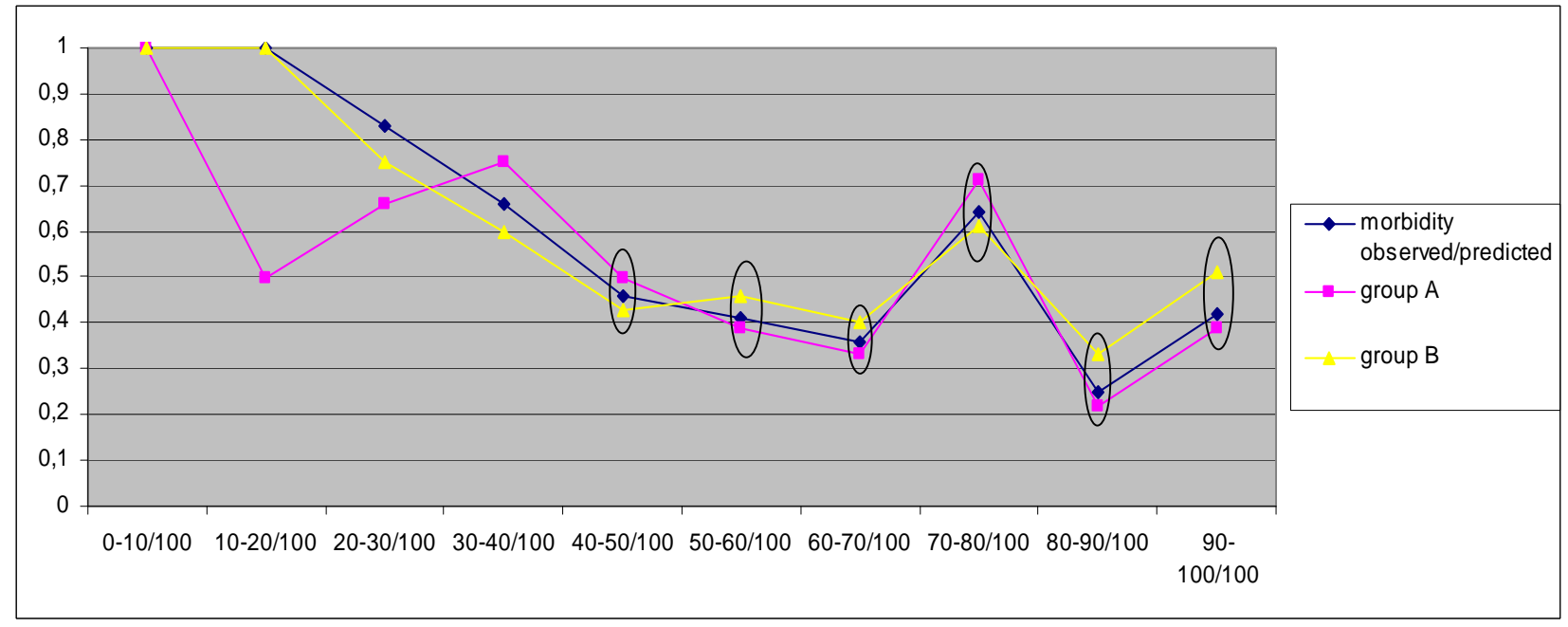

Fig. (1). Correlation between morbidity in group A and morbidity in group B.

The second endpoint concerned the correlation between time of hospitalization in ICU and POSSUM score of predicted morbidity.

\section{PATIENTS AND METHODS}

Our study included 189 patients, all admitted to Intensive Care Unit (ICU) at S.Andrea Hospital in Rome. The sample was divided in 2 groups: group A, abdominal surgery; group $\mathrm{B}$, extrabdominal surgery.

All types of surgery were included except for cardiac surgery, pediatric surgery and urgent surgery. For each patient the POSSUM score was determined. Age, sex and preoperative information, surgical diagnosis, severity of the procedure, time of hospitalization, post operative complications were also recorded.

The two groups were divided in classes, based on the rate of morbidity and mortality. For each class the relation between predicted and observed decease was calculated, and the relation between predicted and observed complications, scoring 1 if present and 0 if not present, in order to assign a reliability score to each group. Furthermore, on the basis of the length of stay, were individuated three subgroups of patients: hospitalization $<3$ days, between 4 and 7 days, $>7$ days. For each group the correlation between observed and predicted morbidity was evaluated.

\section{RESULTS}

On 189 patients, 49 developed postoperative complications, with a real morbidity rate of $25,9 \%$ (95\% CI: $20 \%$ $32 \%$ ) and a predicted rate of $51,3 \%$; the relation between observed and predicted complications $(\mathrm{O} / \mathrm{P}$ ratio) was 0,50 . For the A group the $\mathrm{O} / \mathrm{P}$ ratio was 0,45 , with a real morbidity rate of $25,53 \%$ (95\% CI: $17 \%-34 \%)$ over a predicted rate of $56,4 \%$. In the B group the $\mathrm{O} / \mathrm{P}$ ratio was 0,53 , with a real morbidity rate of $26,31 \%(95 \% \mathrm{CI}: 17,2 \%-34,8 \%)$, and a predicted rate of $49 \%$. Above 189 patients, 5 deceased, with a real mortality rate of $2,64 \%$ ( $95 \%$ CI: $0,4 \%-4,8 \%$ ), over a predicted rate of $16,4 \%$; the relation between observed and predicted deaths $(\mathrm{O} / \mathrm{P}$ ratio) was 0,16 . For the $\mathrm{A}$ group, $\mathrm{O} / \mathrm{P}$ ratio was 0,11 , with a real mortality rate of $2,1 \%(95 \% \mathrm{CI}: 0$ $5 \%$ ) over a predicted rate of $18,08 \%$; for the $\mathrm{B}$ group, $\mathrm{O} / \mathrm{P}$ ratio was 0,25 , with a real rate of $3,16 \%(95 \%$ CI: $0-436,7 \%)$ over a predicted rate of $12,63 \%$. Correlation between time of hospitalization and POSSUM morbidity has an average strength expressed by a $\rho$ value $=0,4$. (Fig. 1)

\section{CONCLUSIONS}

Observed data confirm the possibility to extend the POSSUM score in the stratification of patients undergoing extrabdominal surgery. Even though it overpredicted the value of morbidity and mortality, as widely known [6], POSSUM score shows an impressive uniformity and concordance between the main groups A and B. Furthermore, there is a good correlation between time of stay in ICU and the POSSUM morbidity.

Our results suggest that POSSUM can be an adequate perioperative tool, recommended to evaluate the real condition of a patient after surgery and to determine the requirement of an admission to the postoperative ICU.

\section{CONFLICT OF INTEREST}

The authors confirm that this article content has no conflicts of interest.

\section{ACKNOWLEDGEMENT}

Declared none.

\section{REFERENCES}

[1] Jones HJS, Cossart LD. Risk scoring in surgical patients. Br J Surg. 1999; 86(2): 149-57.

[2] Copeland GP, Jones D, Walters M. POSSUM: a scoring system for surgical audit. Br J Surg 1991; 78(3): 355-60.

[3] Copeland GP, Sagar P, Brennan J, et al. Risk-adjusted analysis of surgeon performance: a 1-year study. Br J Surg 1995; 82 (3): 40811.

[4] Curran JE, Grounds RM. Ward versus intensive care management of high-risk surgical patients. Br J Surg 1998; 85(7): 956-61. 
[5] Cavaliere F, Conti G, Costa R, Masieri S, Antonelli M, Proietti R. Intensive care after elective surgery: a survey on 30-day postoperative mortality and morbidity. Minerva Anestesiol 2008; 74: 459-68.
[6] Whiteley MS, Prytherch DR, Hygens B, Weever PC, Prout NG. An evaluation of the POSSUM surgical scoring system. Br J Surg 1996; 83(6): 812-5.

(C) Alampi et al.; Licensee Bentham Open.

This is an open access article licensed under the terms of the Creative Commons Attribution Non-Commercial License (http://creativecommons.org/licenses/ by-nc/3.0/) which permits unrestricted, non-commercial use, distribution and reproduction in any medium, provided the work is properly cited. 